\title{
The Current Situation of Field Tourism Industry in Primary and Secondary Schools and the Development and Practice of Art Characteristic Courses
}

\author{
Chao Liu*, Mingjun Gao \\ College of Art and Design, Wuhan Textile University, Wuhan, Hubei, China \\ *Corresponding Author.
}

\begin{abstract}
With the rapid growth of material and cultural needs, the development of domestic field tourism industry has aroused heated discussion. The existing researches mainly focus on the macroscopic aspects such as the exploration of the research path, the constituent elements and the policy support.I.[1] Although these studies have initially answered the theoretical questions, there are still some shortcomings in time, such as the lack of research from the perspective of art, the lack of interesting practical results, and the situation of "research" instead of "learning" caused by geographical restrictions or humanistic spirit constraints. Based on the above influences, this study is divided into three chapters. The first chapter analyzes the relationship between study Tours and art courses. The second chapter puts forward the key content of the development of art characteristic curriculum. The third chapter designs and develops the concrete course plan of the three stages. This paper proposes a new concept of art education for the current research curriculum.
\end{abstract}

Keywords: field tourism industry, Artistic Characteristics, Curriculum Dimensions, Aesthetic Cultivation

\section{Introduction}

The establishment of the Ministry of Culture and the Ministry of Tourism has realized the integration of culture and tourism in the administration. As people's continuously improving cultural needs and cultural differences continue to emerge, tourism resources and culture are closely combined Error! Reference source not found.. In order to achieve long-term survival and development under the background of cultural and tourism integration, it is particularly important to create a set of courses that keep pace with The Times and meet the needs of all classes.

First starters, through literature research, this paper sorts out the development of art courses at home and abroad in the past, summarizes and summarizes the initiatives and experience of curriculum design, and summarizes the framework of curriculum design and development in this paper. Furthermore, the product analysis of the courses on the market and in schools and other educational institutions is carried out, and the curriculum design is carried out from four aspects, such as scientific and technological invention, exploration of nature, visual art and cultural inheritance. Finally, through the cooperation between the school and the family and the education mechanism, a good communication bridge can be established between them, and practical suggestions are put forward for the future development of research curriculum and policy modification.

\section{The Relationship between Field Trip and Art Characteristics}

It inherits and develops the educational concept and humanistic spirit of "reading ten thousand books and traveling ten thousand miles" in Chinese traditional study Tours. The art course has the advantages of entertainment, participation and maneuverability in the study tour, which can be reflected in each stage of the study tour I.[3].

2.1 Study the connotation of learning tour activities

"Research learning", namely research-based learning, refers to a learning process in which students take the initiative to ask questions, explore and learn in the learning environment composed of teachers and students with

ISSN: 0010-8189

(C) CONVERTER 2021

www.converter-magazine.info 
their own cognition as the center I.[4].

"Research" is the soul of the study tour. Is a way of research-based learning, the purpose is to let the students according to the interest hobby, individual differences in ability for group assignment, has formed a inquiry, cooperative, interest group, in the process of participation experience art, life, sharing of cooperation, broaden the horizons, enhance the team cooperation ability, to the overall goal into an open society.

"Learning" is the essence of the study tour. In order to let students learn knowledge and skills, cultivate emotional and aesthetic ability. Through participating in the courses with artistic characteristics, I can feel the significance of teamwork and learn natural and cultural knowledge such as geography, local cultural characteristics and climate characteristics. Cultivate students' aesthetic ability.

"Tour" is an auxiliary way for "research" and "study" activities, and research and study activities need to be carried out in the form of "travel". "Tours" can be carried out in three ways: on campus, off campus and in public institutions. It is specifically reflected in the setting of the activity plan, which includes time, place, activity route, course objectives and content.

\subsection{The significance of art courses in the process of research and learning tour}

The interest of art course can make students improve their learning enthusiasm. Exploring the theme of nature can stimulate students' love for nature by organizing them to participate in nature activities, and cultivate their sense of responsibility and cooperative spirit in the activities I.[5]. Art courses enable students to understand how the nature and society are beautiful, understand the beauty between human and nature, human and society, is to observe the world with the eyes of art, is to train students how to use the vision of art. The ability to see the world independently. Art courses help students discover inner beauty. At present, primary and secondary school students in this stage, in daily life may spend more time and energy. In the process of pursuing beauty, we should set up the correct aesthetic concept and sublimate the external beauty into the internal beauty.

\subsection{Difficulties faced by art courses in the process of research and learning tour}

The huge market attracts the transformation of major institutions, the market access threshold is low, the research market is mixed, the curriculum design is uneven, the research curriculum due to the lack of professional practitioners, resulting in the lack of art curriculum artistic and interesting. Because art course is a novel course, it is not sufficient in the theoretical exploration and practice process, and the family and school attach too much importance to the results of cultural courses and exclude the courses with entertainment.

The lack of attention from parents and the disconnection between research institutions and school education lead to the lack of comprehensive communication among the three aspects, which hinders the development of research courses with artistic characteristics from many aspects. The evaluation of study achievement is the last step of study tour.

The evaluation mechanism of research achievement should be introduced, and evaluation scales should be designated according to different research objectives, content and age characteristics, so as to comprehensively and objectively evaluate students' research behavior. The diversity and all-around evaluation mechanism can run through the whole art course, affecting students' learning enthusiasm and self-confidence, and related to the cultivation of students' innovative spirit and respect.

\section{The Key to the Development of Art Characteristic Courses}

3.1 Dimensions of art curriculum development

ISSN: 0010-8189

(C) CONVERTER 2021 
Art education should be truly oriented to all students. In the vertical dimension, it should provide equal opportunities for each student's growth stage and development, and in the horizontal dimension, it should broaden the types of courses and knowledge area. The vertical age division dimension is adopted to fully respect the survival and development rights of students, and to recognize and maintain the individual differences of students in art. In each stage, students will have different characteristics and needs. According to different ages and stages, a loose space and time environment is created for students to study and play freely in art. Horizontal curriculum development should be adopted to fully respect students' dominant position in education I.[6]. Teaching content, methods and evaluation should be student-oriented and learning-oriented. Expand the horizontal area of the art course to meet the needs of students' all-round development, and embody the students' training knowledge and skills, process and method, emotional attitude and values in the course development.

\subsubsection{Longitudinal division of age segments}

Age is an important social variable in the research market segmentation, and different age structures have an important impact on the research market. Professor Yang Jingzhi, a Chinese art educator, roughly divided Chinese children's painting into five stages, from which this study extracted three stages: image expression period (5-8 years old), early visual realism period (8-12 years old) and objective realism period (12-15 years old) to divide art curriculum into stages.

The cognitive ability and understanding ability of Grade 1 and Grade 2 students have also improved significantly. At this time, we can design the curriculum according to children's curiosity about nature. Third grade students' subjective consciousness is strong, and children's observation ability, imagination ability, creative ability and image memory ability are cultivated. Students in Grade 5 or 6 at this time, facing the pressure of rising from a junior high school to a junior high school, tend to have realistic painting ability. In view of this, some courses of art theory can be added appropriately.

The students who have just entered junior high school are in the early stage of realism I.[7]. The goal is to make students understand the ability of color recognition, establish their own painting consciousness, discover materials and establish their own painting reference. The curriculum design can provide some related basic theoretical knowledge of fine arts for junior high school students who are in the stage of primary promotion, and provide some theoretical support for the objective realistic period of high school.

The self-cognition and level of high school students have been improved, as well as the ability to think independently and deal with things. In character, they are fond of doubt, exploration and curiosity, debate, and easy to accept new things. At this time, it is particularly important for the systematic cultivation of artistic theoretical knowledge and the activities of sketching and collecting styles.

\subsubsection{Horizontal development of course width}

The development width of middle school students' art characteristic courses is carried out according to age segments. In the traditional sense, basic knowledge and basic skills will no longer be the whole or main connotation of the basic art education in primary and secondary schools. In order to meet the needs of students' allround development, this research divides the ages of primary and secondary schools into corresponding width of curriculum development I.[8].

The interest of art curriculum stimulates the curiosity and creativity of primary school students. For primary school students aged 5-6, the courses of natural resources such as mineral collection are set according to the curiosity of students at this stage, which meets the requirements of students at this stage. The classroom door organizes the students to go on a hiking trip to the nearby countryside. During the trip, they collect leaves, stones, ores and other specimens to make bookmarks or keep as memorials. Elementary school children between the ages of 8 and 11 can make some clay figures or clay patterns.

ISSN: 0010-8189

(C) CONVERTER 2021 
The diversity of art curriculum to cultivate the ability of junior high school students to study on their own. Junior high school students are different from primary school students, as the area of contact with life is expanded, the scope of knowledge is also expanded. The curriculum adopted is also varied. Students of Grade 1 can do some still life paintings and understand the basic principles of painting. Students in Grade 2 are organized by teachers to carry out research activities in the museum and participate in some intangible cultural heritage activities. Students in Grade 3 offer calligraphy and traditional Chinese painting courses to learn about the beauty of traditional art.

Aesthetic soundness of art curriculum Aesthetic ability of high school students. Due to the heavy cultural courses for senior high school students, their intellectual development has reached maturity at this stage, which is an important period for the formation of outlook on life and world view, as well as the development of knowledge and ability. The cultural inheritance section is mainly divided into three parts, namely, calligraphy aesthetic appreciation and practice, landscape painting and museum research. To construct the aesthetic cognition system of senior high school students from three forms, to cultivate the aesthetic taste of senior high school students by the appropriate output of aesthetic education knowledge, so as to establish a correct aesthetic concept and value concept.

\subsection{Practical projects in art courses}

\subsubsection{Explore natural topics}

Exploring nature enables students to learn to use various senses to obtain information and understand basic forms such as climate, vegetation and animals. Through the perception and description of nature, students can sharpen their observation ability. Students can experience the wonderful effects of hearing, smell, taste and touch through the design of the study tour course. It can inspire students' love for nature, and cultivate students' sense of trust and cooperation.

In the course of the journey by collecting local minerals, plants and so on as specimens, with dried, made into ornaments by soaking and lose money making collection and appreciation, this way can vaginal students actively in the process of making the area of knowledge, to explore the nature, find a wide variety of plants, find its colour, line, taste, etc., It is beneficial to cultivate students' ability of observation and thinking, and improve students' understanding of natural beauty.

\subsubsection{Visual art topics}

Visual art can express an inspiration or experience through techniques and media, so that it can be realized visually. Specific can take the form of painting graffiti, clay sculpture, photography, specimen making and so on. The expression of visual art is embodied in

Lines: the dynamic and static lines indicate the direction and divide the shape space. For example, when you go to a place during a study tour, you can draw a map in the way of lines to deepen the memory of the area. Lines can also show the volume or solid surface, which can be used to show houses, buildings or all kinds of still life. Lines can also be combined to form light and shadow, patterns and textures.

Color: color is the most active factor in visual communication. Color recognition and symbolism play an important role in the performance of primary and middle school students. For example, cool and quiet blue and green colors should be used to represent mountains and rivers, while energetic red and yellow colors should be used to represent sunset. Trees are associated with warmth in spring and summer, male animals are associated with virility and so on. So in the application of color respect cannot be mechanically applied, should be used flexibly.

When students are drawing sketches, they can introduce some related art theories, such as $\mathrm{S}, \mathrm{X}$ and other composition methods, basic painting principles such as near big far small, near real far virtual, etc. Through lines and colors, students can experience the fun of modeling, dare to innovate and transform, and generate lasting

ISSN: 0010-8189

(C) CONVERTER 2021 
interest in artistic creation.

\subsubsection{Cultural inheritancet topics}

In general, primary and middle school students are not interested in the articles on cultural inheritance in textbooks, so they can stimulate their interest in traditional culture through some special courses ${ }^{\text {I.[9] }}$.

First of all, schools or research bases can carry out some ethnic cultural activities, such as holding "61" art performances, parties and so on. Ethnic minority students can be encouraged to perform or play their own ethnic songs, dances and Musical Instruments in the art performances, so as to stimulate ethnic minority students' sense of identity and pride in ethnic culture and arouse ordinary students' interest in other ethnic cultures.

Secondly, cultural guessing games can be held in cooperation with the community. Through group cooperation, guessing in pairs can be set up and an incentive mechanism can be set up. Let the students in the game to acquire cultural knowledge, there can be in the activities to learn cultural knowledge than pure books to more direct and deep impression.

Finally, in the inquiry learning activities through some painting means record in the local humanistic feelings, can take in a variety of forms, through the line and color painting record, also can make bookmarks, sketch map routes, etc., to deepen the impression has a strong local culture, studies the base held on display at the end of the activity, let students to review their studies, Communicate with each other. Finally, the experience of research and study is summarized.

To sum up, from a macro point of view, there are three ways that art courses can promote the inheritance of national culture: one is to carry out entertainment activities for students to participate in, so as to acquire the sense of entertainment of cultural knowledge; the other is to acquire cultural knowledge through quiz games. The last one is to exchange people's different views on local culture through the exhibition of works, which is beneficial to stimulate students' desire to explore culture.

\section{Primary and Secondary School Research Curriculum Practice Research}

\subsection{Elementary appreciation course design scheme (5-10 years old)}

Primary appreciation course is aimed at around the age of 5-10 primary school, the purpose is to cultivate pupils close nature, arouse students interest and love for nature, when elementary school students have the interest, will take the initiative to establish contact with nature, in the time observation, experience and comprehension, and writing, to appreciate the charm of nature and the goodness of life. The program cultivates students' ability of faith, perseverance, cooperation, sharing and communication.

Understand local geological features, topographical features, climate and vegetation through ore collection; Through hiking at night, students can experience the opportunities of darkness, observe the opportunities at night, and observe the stars to help them understand the changing stars; For example, the course of paper cutting will be taught by the craftsmen on the spot to explain the safety precautions, accompanied by parents, and the development process of paper cutting book will be explained. Then the teacher will demonstrate the practical operation, and finally the students will create the paper cutting book by themselves. These three courses can increase children's hand-eye coordination skills and enhance parent-child communication.

4.1.1 Ore collection (5-6 years old)

The age of 5 or 6 , around the time children are in first grade, is the golden age for imaginative subjective feelings. During this period, children did not like very realistic painting, so organizing and participating in activities to explore nature could maximize students' learning enthusiasm. China is rich in mineral resources, such as Handan,

ISSN: 0010-8189

(C) CONVERTER 2021 
Anshan and other northwest areas, the classroom door can organize students to collect samples according to the local characteristics of the mineral, let the students to collect samples for comparative analysis, to understand the shape, characteristics, color and function of different ores (table1). Experience the freshness of the outdoor research. Teachers can publicize the students' analysis results after the activity.

Table 1 Ore collection project

\begin{tabular}{|c|c|c|}
\hline The target & Practice process & Curriculum evaluation \\
\hline $\begin{array}{c}\text { Experience the novelty of the } \\
\text { outdoors }\end{array}$ & divide into groups & On display \\
\hline $\begin{array}{c}\text { Understand the shape, color and } \\
\text { characteristics of the ore }\end{array}$ & Hiking in Groups & Making Portfolio \\
\hline $\begin{array}{c}\text { To improve the students' observation } \\
\text { ability }\end{array}$ & $\begin{array}{c}\text { Collect ore and fill in ore } \\
\text { characteristics }\end{array}$ & \\
\hline
\end{tabular}

4.1.2 Observe nature (7-8 years old)

Our country is vast, beautiful scenery, east and west, north and south obvious differences, four distinct seasons, natural observation is conducive to the cultivation of students' observation ability, the improvement of observation ability can help us be good at finding problems and solving problems. Curriculum design can be based on the characteristics of different areas to explore the nature activities. Can set the route, goods preparation, travel record. Through the compass, solar orientation, star-moon orientation, orientation to map recognition (table 2). Through these methods, they understand the monsoon climate, geographical features, regional specialties and so on in each region.

In fact, the course of observing nature has great benefits. Regular observation of nature, through some games and activities, can make children more imaginative. Let the children's observation more acute; To increase children's concentration; While building up children's willpower, it also makes it easier for them to express emotions; Over time, children who observe and interact with nature can also lead and influence other children to become nature guides.

Table 2 Observe nature project

\begin{tabular}{|c|c|c|}
\hline DAY1 & DAY2 & DAY3 \\
\hline Drowning safety education & $\begin{array}{c}\text { Understand the climate and } \\
\text { geomorphological features } \\
\text { Collect specimens and make } \\
\text { specimens or bookmarks }\end{array}$ & Use a compass \\
\hline Aise awareness of outdoor risks & Introduction to special scenic spots & Draw the route of study \\
\hline Knot course teaching
\end{tabular}

4.1.3 Handmade ideas (9-10 years old)

Students may have different views on different landscapes or historical legends during their research and study trips, so they can do some handmade works. To Wuhan yellow crane tower inquiry learning activities, for example, can be used on the canvas to draw the image of yellow crane tower, in the period of the students, the teachers taught some basic principle of art, such as the complementary color, contrast of changes in temperature, a little perspective, nearly solid far and near small, and so on, through composition, line and color let students experience the fun of the model, dare to carries on the creation and performance, Develop a lasting interest in the study of fine arts. If you cannot go to the local research activities, paper-cutting activities can be carried out in class.

According to the traditional arts and crafts and regional characteristics, the courses of different professional directions are provided for the arts and crafts major. The intangible cultural heritage of traditional craft into primary and secondary schools of arts and crafts professional courses for teaching, including specification of classroom learning, and expand the learning outside the classroom, emphasis on theory, and attaches great importance to the practice, to enrich and enriching the connotation of the existing industrial arts courses, formed subject to fusion, is advantageous to the non-material cultural heritage of the inheritance, protection and innovation.

ISSN: 0010-8189 
It is of great significance for the construction of characteristic courses and the enhancement of students' professional skills and artistic accomplishment.

4.2 Curriculum design scheme for intermediate participation (11-14years old)

Children between the ages of 11 and 14 are in junior high school. According to the psychological characteristics of junior high school students in this period, they are lively in thinking, heavy in curiosity but weak in will. The curriculum is designed to guide students to acquire the beauty of color and line from nature by learning to make animal and plant specimens. Understand the knowledge of perspective, color ring and other art theories in still life painting; Feel the natural scenery in the photography practice course; To understand the excellent traditional culture of China in the course of intangible cultural heritage cognition. The four courses of specimen making, still life painting, photography practice and intangible cultural heritage cognition guide students to carry out a profound research and learning journey through independent learning, communication and collaboration, problem exploration, practical operation and other learning methods.

\subsubsection{Specimen preparation}

There are various forms of taxidermy. Teachers or research bases provide materials, such as watercolors, cardboard, crayons, bookmarks, canvases and other fixed materials. Form after fixed, the students can participate in the design and creation, for example, xingshan county, the hometown of wang zhaojun, manual curriculum development, by means of a photograph of xingshan county characteristic landscape water road extraction, the extraction of cultural elements and local characteristics, the students can do it through the bookmarks, or painting, manual, etc., can be in the painting or hand in learning to the characteristics of the local culture. Taking the initial experience of specimen making as an example, the following study process is set up.

The first step is the popular science class "Specimen Tracing to Source". The questions raised by the research tutor will trigger the students' thinking, and then the research tutor will explore the types and technological processes of specimen making, actively think through the learning methods such as discussion, experience, perception and creation, observe different forms of specimens, and actively discover the secrets of specimens.

Second, the taxidermy museum explores "Brainstorm." Through theme explanation and exhibition design, students were asked questions, brainstorming, zero-distance observation field, application of multimedia equipment in the museum, group cooperation and other ways to explore questions. After a heated discussion, the group sent representatives to make a presentation and report

Step three, the taxidermy record "My Specimens". Specimen making is an interesting art, but also an art about "life". It is demonstrated by the tutor of the Museum of Specimen Art. Students work together in groups to use interactive experience instead of one-way output teaching, so that the sparks of ideas can burst out.

4.2.2 Drawing still life

12 years old children in the time of entering high school, at this time due to the expansion of the contact area of the world and the life has the concept of realism, still life painting is a kind of common art activities, through depiction of fixed objects, can cultivate students at this time for a better understanding of the volume, composition, light and shade. For the still life drawing course, it can add a new possibility for students to enter high school.

\subsubsection{Photography practice}

Photography is an art of observation and an important part of fine arts education. Travelling in the inquiry learning in junior middle school students in a class time is very difficult to have sufficient time to think, analyze, and conceived down during their students it is sometimes hard to sketch works created to bring their satisfaction, and photography can to perform work in an integrated way, it can serve as an auxiliary form became a junior middle school fine arts teaching way of creation. The timeliness of photography also helps students to capture beautiful

ISSN: 0010-8189

(C) CONVERTER 2021 
moments, which can play a good role in research and study activities. Students learn photography from a camera at an early age, which not only brings infinite joy to children, but also improves their aesthetic taste and artistic temperament, as well as their ability to observe details, express emotions and recognize the structure of things.

4.3 Curriculum design scheme for later creation (13-senior high school)

Later creation courses correspond to the high school stage. During this transitional period for teenagers, the course aims to develop students' ability to observe, imagine, and think in images, adjust their daily life, and improve their learning. Through training senior high school students to the origin of the recognition of calligraphy, feel the beauty of Chinese characters; Scenic sketching stimulates students' love of natural scenery such as mountains, rivers, stars and moons, rivers and lakes. Museum research can extend the historical knowledge learned in previous classes to specific cultural relics and deepen understanding.

\subsubsection{Calligraphy aesthetics}

Through video appreciation, students are guided to appreciate the beauty of ancient Chinese characters and traditional culture, understand the development and evolution process of Chinese characters, and stimulate their love for traditional Chinese culture and national pride. Secondly, through the source of calligraphy to feel the unique beauty of Chinese characters. Finally, students can gain aesthetic perception and improve their aesthetic quality through homework display (table 3).

Curriculum design will also through the scene of the teacher interaction and demonstration, so that the students could feel picture charm, further review consolidate, flexible use of picture composition, the basic method of line, further deepening the cognition and understanding of oracle, experience the fun of calligraphy and painting blend with aesthetic feeling, experience he stooped down, and unique flavor.

Table 3 Calligraphy aesthetics project

\begin{tabular}{|c|c|}
\hline Calligraphy origin & Brushwork (center, side peak, eight-sided front) \\
\hline The beauty of form & Post Posting and creation \\
\hline The beauty of picture & Necessity and chance \\
\hline The beauty of rhythm & Artistic conception and state \\
\hline Personality and Emotion & Aesthetics of the Times and Individual Choice \\
\hline
\end{tabular}

\subsubsection{Museum research}

Confirm the purpose of this study, acquire knowledge and understanding of the cultural relics in the collection and enrich the structure of historical knowledge at the cognitive level ${ }^{\text {I. }[10]}$. On the value level, it can stimulate students' fun, inspiration and creativity, trigger thinking, form positive attitude and values, and enhance cultural confidence. The pre-test will ask three questions: What do you know about this study? What would you like to know? What have I learned after studying?

Set personal learning goals, individual independent learning, hand stop. After clarifying the learning objectives, I went straight to the area I was interested in for a precise visit. I recorded important information in the form of key words and drew cultural relics in the form of stick figure.

During the course, the teachers and students participated in the class, and their mouths did not stop. Some museums do not have interpreters. In order to answer students' 100,000 questions, teachers have to make a lot of preparations before marching.

After the group team discussion, noisy. There is a time limit for the seminar. In order to achieve the best research results, students can work together in groups to complete the research tasks. Record, measure, draw, color, consult, summarize, take photos and so on.

ISSN: 0010-8189 


\section{Conclusion}

There are two key points in the design and development of the art curriculum of "study tour" in primary and secondary schools. One is the vertical division of students' ages; the other is the expansion of curriculum width according to age characteristics and students' psychological characteristics. From the perspective of artistic characteristics, it fully arouses students' enthusiasm for research and study. The horizontal course width is divided into primary appreciation course, intermediate participation course, later creation course, and down to specific courses, which can cater for different needs of different ages.

Today's education is not only imparting knowledge, but teaching people to fish, and designing art courses with new educational concepts. From the exploration of nature, visual arts to cultural inheritance to cultivate students' aesthetic concepts and establish correct values; The introduction of evaluation mechanism enables students to have a clear sense of cognition and experience of the whole research activities, and gradually approaches the goal of comprehensive development, which can truly reflect the integrated effect of "research" + "study" + "travel"Error!

\section{Reference source not found..}

\section{Acknowledgements}

This work was supported by Foundation Project of 2019 National Social Science Foundation Art Science Project, Research on the Cultivation Mechanism of Public Art on Youth Values, (Project No. 2019a01315).

\section{References}

[1] L. Wu, H. Liang, H.J. Yu, R.M. Huo, "Spatial differentiation and driving factors of the integrated development of culture and tourism in China."

[2] Y.X. Xu, "Rend Measurement and Evaluation of Cultural Industry and Tourism Industry Integration Based on Coupling Model -- Taking Zhejiang Quzhou City as an Example,” Jiangsu Business Theory, vol. 05, 2019.

[3] Y.H. Kong, "Path Selection of the Integration Development of Tourism Industry and Cultural Industry -- A Case Study of Hebei Province," Social Science Forum, vol. 10, 2016.

[4] X.O. Wu, X.F. Gao, "Research on the Government Guarantee Mechanism for the Integrated Development of Culture and Tourism Industry -- Taking Zhangjiakou as an Example," Journal of Hebei North University (Social Science Edition), vol. 01, 2014.

[5] C.H. Deng, F.R. Sun, Z.H. Li, "The connection between field trip and school curriculum from the perspective of embodied cognition," China Education Journal, vol. 10, pp. 82-86, 2020.

[6] S.D. Yin, J. Cheng, "The value implication and practical path of curricular travel in primary and secondary schools," Curriculum, Textbook and Teaching Method, vol. 38, no. 4, pp. 116-120+115, 2018.

[7] J.Q. Yang, "Reflections on Course Cohesion," Courses, Textbooks and Teaching Methods, vol. 35, no. 8, pp. 10-15, 2015.

[8] M.H. Yu, "The implementation of field trip needs to go through 'four passes'," China Tourism News, 2016-12-21 (003).

[9] N.X. Cao, L. Wang, "On the Methods of Promoting National Culture Inheritance through Education," Journal of Yunnan Normal University (Philosophy and Social Sciences Edition), vol. 42, no. 02, pp. 119-124, 2010.

[10] X.X. Guo, "Research on the implementation direction of field trip curriculum from the perspective of space," Comprehensive Education and Social Sciences, 2020

ISSN: 0010-8189 